\title{
PRÁTICAS RADIOFÔNICAS: AÇÃO, CONTRACENAÇÃO E ESCUTA
}

O trabalho apresenta um relato e reflexão a partir de práticas radiofônicas com texto dramático, com alunas-atrizes no âmbito da formação universitária. Discute o sistema proposto para o exercício e traz considerações sobre elementos da atuação para o rádio tais como contracenaçao, voz e escuta.

Palavras-chave: peça radiofônica, escuta, contracenação.

\section{Abstract}

The work presents an account and reflection from radio practices with dramatic text, with students-actresses in the context of university education. Discusses the system proposed for exercise and brings elements of the performance considerations for the radio such as coact, voice and listening.

Keywords: radio play, listening, coact. 


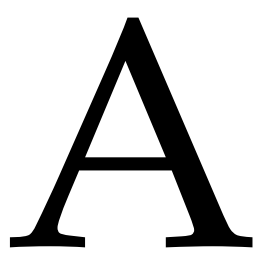

presenta-se

aqui um breve relato de experiência com práticas radiofônicas. Embora na atualidade o gênero peça radiofônica esteja pouco presente em rádios brasileiras, ainda se apresenta de diversas formas em outros países, em especial na Alemanha, Espanha e Inglaterra. No nosso caso, temos nos debruçado sobre as possibilidades pedagógicas do exercício radiofônico não apenas no que diz respeito à apropriação da linguagem, mas também como meio de alargamento dos estudos sobre a palavra, o tempo, a escuta e o silêncio, na formação de atores.

Nas palavras de Fernando Peixoto (1980, p.8), “estamos diante do som trabalhado enquanto material básico para a construção de obras definitivas que instauram uma linguagem avassaladora (...) no qual palavra e som, ruídos e silêncios, ou mesmo música, propõem a partir de efeitos técnicos e/ou humanos, uma realidade criativa surpreendente e até mesmo, transformadora".

Para este exercício, duas alunas-atrizes que já trabalhavam juntas há algum tempo e, habituadas com o sistema de trabalho gravações, audições, microfones, estúdios - buscavam um texto/provocação para o trabalho. A experiência anterior, com um texto bastante denso de Pinter, havia trazido uma inquietação criativa e várias indagações. Uma delas dizia respeito ao falar, a fugir do óbvio, coisas que havíamos experimentado nos exercícios de espaço. A ideia era fugir do que estava "pronto", desmanchar uma forma convencional de dizer. Procurar uma lógica do som, trabalhar as palavras, variar a duração da fala, suspender a pausa, foram algumas das possibilidades trabalhadas. Para Fortuna (2000, p.70), "a atitude do ator

1 Atriz e radialista. Doutora em Educação pela UFRGS. Professora e pesquisadora no Departamento de Arte Dramática e Programa de Pós-Graduação em Artes Cênicas, UFRGS. Coordenadora dos Projetos de pesquisa $O$ trabalho do ator voltado para um veículo radiofônico e Ator e vocalidade. Menção honrosa no Prêmio Nossa Onda, do MINC, 2011, com a peça radiofônica Guarda-Roupa. com a oralidade consiste muitas vezes em perverter pontuações eletivas à sintaxe, transgredi-las, desordená-las, tira-las do lugar, em nome da chamada instantaneidade da vivacidade oral".

Trabalhamos sobre exercícios que buscavam a contracenação, tema que herdáramos da fase anterior. Fizemos então a escolha de outro texto de Harold Pinter, ${ }^{2}$ Problemas no trabalho. A situação aqui era de uma comédia que pendia para o absurdo. Além disso, o ritmo das falas, a estrutura dramatúrgica apoiada na estranheza do assunto, eram muito sugestivos para um exercício radiofônico, no meu entendimento. Aquecidas pelo exercício anterior, as duas alunas-atrizes, se entregaram com prazer ao exercício e à comicidade do texto.

No texto, duas mulheres se encontram no escritório da dona de uma fábrica. A empregada vem, respondendo ao chamado da chefe, para dizer o que está acontecendo na fábrica e esclarece que as funcionárias não estão satisfeitas com os produtosfabricados pelaindústria. As duas passam a descrevê-los. Entre a surpresa da empresária e o constrangimento da funcionária, as mais absurdas peças de reposição são descritas, até o insólito final, em que é dito que as funcionárias querem produzir balas de licor.

Iniciamos este exercício fazendo as primeiras leituras sem definir que atriz faria qual personagem. Desta forma nos detivemos na situação da peça e nas possibilidades do cenário sonoro. Revezávamos a leitura dos personagens e, inclusive eu li cada vez com uma delas para que a outra ficasse apenas na escuta.

Evidenciou-se aqui um elemento essencial da construção radiofônica que é o cenário sonoro ou ambientação sonora. Insubstituível, esse elemento funciona como a base para a imaginação do ouvinte. Ele localiza espacialmente a ação e coloca

2 Harold Pinter, dramaturgo inglês nascido em 1930. Suas obras, usualmente são associadas ao Teatro do Absurdo. 0 humor e o mistério estão presentes em muitas delas. As mais conhecidas são Festa de aniversário e Terra de ninguém. 
o ouvinte dentro do mundo da ficção radiofônica. Sendo realista ou mais abstrato, ou utilizando ruídos do cotidiano ou trilhas musicais, o cenário sonoro traz o ouvinte como parceiro da ação e da imaginação. Os ambientes devem tornar-se "visíveis" através da sonorização. A ambientação sonora tira o caráter estático da "montagem de teatro gravada" e oferece indicações de espaço diferentes daquelas referidas pela fala dos personagens.

Para Schafer (1991), o mundo está coberto de sons e as paisagens sonoras são muito diversas. Esse mundo é tratado por ele como uma grande composição constituída por qualquer coisa que soe. No caso do radiodrama, ou da audioarte em geral, também precisamos construir um mundo acústico. Assim, para engendrar a ação radiofônica, profundamente calcada na palavra e na voz que a pronuncia, necessitamos compor as paisagens sonoras desta situação.

Assim, a palavra e o seu dizer, em paisagens sonoras das mais variadas matizes, adquire dimensões de infinitas possibilidades. Klippert (1980, p.81) afirma que "a palavra projeta o mundo da peça radiofônica. Para que este mundo se torne existente, para isto é necessária a voz que o represente".

Nossas primeiras impressões do texto nos levaram a trabalhar em alguns aspectos da adaptação como, por exemplo, dar os nomes dos personagens que no original são só chamadas pelo sobrenome. Assim, escolhemos os nomes que as mulheres tinham. Deste modo, a Sra. Fibbs, a empresária, se chamaria Virgínia e a Sra. Wills, a funcionária, teria o nome de Zuleika. A necessidade dos nomes surgiu também, pois decidimos que no decorrer da ação da peça a funcionária iria gradativamente deixando de chamar a chefe de Senhora e passaria a chamála pelo nome, Virgínia, demonstrando assim uma certa intimidade mascarada pela função de ambas. Cogitamos até que as duas seriam muito amigas, apesar da separação de classes. Este foi um elemento muito interessante para a contracenação.
As leituras, a partir deste momento, já tinham a definição dos papéis. Numa combinação do desejo das atrizes com a minha sugestão, chegamos a uma distribuição que privilegiava o desafio para a tarefa. A escolha delas voltava-se para o tipo de personagem que não haviam feito ainda, que lhes causava mais inquietação. Mesmo que já tivéssemos lido o texto com as diferentes combinações de personagens, incluindo a minha voz, usamos ainda o exercício da troca de papéis, o que reforçava a escuta sobre texto.

À medida que trabalhávamos mais entendíamos que o texto tinha uma situação realista para um tema absurdo. Era interessante fazer as duas mulheres conversando de forma bastante natural de coisas que aparentemente não faziam sentido. Para essa composição utilizamos bastante o exercício de exagerar. Queríamos marcar a diferença com a fase anterior e soltar as vozes e intenções.

Foi muito rico enfatizar a relação patrão $X$ empregado tendo como subtexto a amizade das duas mulheres. Num determinado momento, nos colocamos a questão da funcionária, Sra. Zuleika: afinal ela está com as colegas, concorda com elas? Ou está ao lado da patroa e amiga. Esta dualidade enriqueceu a composição da atriz que fazia este personagem. Experimentamos gravar exagerando as intenções para cada uma das possibilidades, o que foi bastante interessante. A atriz fez com que o personagem carregasse a dúvida e o constrangimento por toda a peça como se estivesse se perguntando a todo instante. Da mesma forma, a outra aluna-atriz investiu no humor do seu personagem, na surpresa com as notícias e, principalmente na relação de amor que a dona da fábrica tem com as peças de reposição que fabrica.

Para ambientar a fábrica lembramos a trilha sonora do filme Dançando no escuro, ${ }^{3}$ cuja música é de Björk. A música e os sons usam a repetição como elemento e

3 Dançando no Escuro (Dancer in the Dark), filme de 2000, do gênero drama musical, dirigido pelo diretor dinamarquês Lars von Trier, que também é o autor do roteiro. 
reproduzem os sons da fábrica do filme. Fizemos uma audição do CD e gostamos muito da ideia. Para o final em que a funcionária revela o desejo do grupo de operárias, pensei numa quebra com música clássica. Na versão final acabei por escolher da trilha sonora de Peer Gynt, ${ }^{4}$ de Grieg, a música de abertura, Amanhecer.

Nesta fase, gravar e ouvir eram a base de tudo. Foi aqui que percebemos que fazer sempre mais de uma gravação, e em sequência, era muito produtivo. Nas palavras de uma das atrizes envolvidas na experiência:: "Constatamos que nas gravações feitas sem pausas, existia um crescente na qualidade da primeira para a última. Desta forma começamos a fazer leituras como aquecimento antes de gravar".

A gravação impedia que cristalizássemos as intenções, pois o intenso acompanhamento da evolução do trabalho nos deixava alerta para qualquer evidência de estagnação. E para manter a verdade da cena. Mesmo no absurdo há uma lógica, uma verdade que move o ator. No rádio expressivo, assim como no teatro, a arte é viva quando o artista está inteiro no trabalho.

Insistimos na necessidade de valorizar a palavra, as pausas, o silêncio e a intensidade das entradas das falas. Preencher a cena radiofônica com a ação sonora. Ao mesmo tempo, encontrar o ritmo da fala e dos silêncios de cada personagem. Essa cadência, esse ritmo revela o estado em que se encontra o personagem neste ou naquele momento. E determina o andamento da ação. É o que refere Eni Orlandi (2002, p.72), "com efeito, a linguagem é passagem incessante das palavras ao silêncio e do silêncio às palavras".

Nossa incursão pelo tempo radiofônico se fazia sentir neste exercício. Percebíamos que o andamento das falas, a duração das intenções necessitavam precisão para

4 Peer Gynt, peça teatral escrita pelo dramaturgo norueguês Henrik Ibsen, publicada em 14 de novembro de 1867, em Kopenhagen, Dinamarca.

5 Notas retiradas dos diários de trabalho das alunas-atrizes durante fase da pesquisa $O$ trabalho do ator voltado para um veículo radiofônico. que se instalasse o humor e a verdade no absurdo, que é dizê-lo como se fosse natural. Familiarizadas com o ritmo da colega, elas experimentavam com facilidade a improvisação deste tempo, variando sua participação em sintonia com a parceira.

Como todo sistema, também o nosso aceitava transgressões. Criamos caminhos, invertíamos etapas, inventamos novos exercícios. O estágio do trabalho ou as características do texto sugerem essas mudanças. O que não abandonamos em momento algum foi gravar/ouvir. Não só isso, como fomos aprimorando e valorizando cada vez mais esse processo. Como registrou uma das alunas-atrizes: ${ }^{6}$ "É diferente de filmar uma cena teatral para analisá-la, pois nesse caso o veículo torna-se o vídeo e deixa de ser teatro. No rádio, a voz/ gravação continua a ser o próprio veículo".

Estávamos lidando com o material próprio da linguagem. O rádio mesmo. Ao mesmo tempo, o processo de se ouvir preparava também para lidar com aspectos técnicos da voz ao microfone. Distância, direcionamento, extremos de agudos e graves, assim como letras sibiladas foram sendo corrigidas no decorrer do trabalho. $\mathrm{O}$ microfone não era um mais estranho, mas um instrumento a ser apropriado como a câmera ou o próprio corpo.

Assim, chegamos aos fones de ouvido. O fone devolve a voz do ator ao mesmo tempo em que ele fala. Para alguns, isto é motivo de ansiedade por ouvir-se, por rejeitar o que não parece ser a própria voz. O fone aperfeiçoa a emissão das falas, pois permite mudar o rumo ou a intenção no momento mesmo da peça. Ao vivo ou na gravação, tem-se sempre a sensação de ser ator e ouvinte ao mesmo tempo, vislumbrar a audição do que se está compondo.

Este recurso dá ao ator a possibilidade de agir sobre seu trabalho em andamento. Dessa forma passa a ter uma consciência maior do controle que tem sobre sua atuação e avança mais definido em relação ao seu objetivo.

6 Notas retiradas dos diários de trabalho das alunas-atrizes durante fase da pesquisa $O$ trabalho do ator voltado para um veículo radiofônico. 
O uso dos fones, assim como outras especificidades da arte radiofônica, estava nesse momento sendo apropriada por nosso trabalho. Assim, mesclávamos as possibilidades de criação do processo teatral com os mecanismos da arte sonora. E ainda, a gravação com fones é o momento em que fica mais evidente a concentração do ator não apenas em si e em seus processos de criação, mas no outro, no efeito de sua voz. Ele é um que fala e outro que ouve. Ao mesmo tempo.

No caso desta peça, em que as atrizes vinham trabalhando juntas há bastante tempo o uso dos fones significou colocar todo o seu foco na escuta. A contracenação passou a acontecer via escutar-se nos fones. Houve um grande ganho no ritmo da peça e na afinação das atrizes. $\mathrm{O}$ jogo da ação deslocou-se para o dizer e ouvir. Aqui a ação de ouvir também passa a ser uma atitude corporal.

Para Balsebre (1994, p.36), os fones amenizam o fato de que o locutor enfrenta uma dificuldade característica do rádio que é construir com a voz a abstração de ouvintes imaginários. E ainda os fones fazem com que o locutor ao escutar-se receba, diz ainda Balsebre (1994, p.36), "uma primeira impressão psicológica da interlocução consigo mesmo".

Habituadas ao exercício compartilhado na especificidade da radiofonização, as atrizes fizeram experiências muito gratificantes em relação à contracenação. No que diz respeito ao uso dos fones nas gravações, perceberam que colocando seu foco na voz da parceira, ouvida pelos fones no momento da gravação, eram capazes de responder ao estímulo da voz e não do olhar ou da ação física. Assim, puderam apontar uma contracenação de vozes, silêncios e engajamento corporal na presença da voz.

Apropriamo-nos, pois, da reflexão de Chekhov (1983, p. 115) sobre contracenação, "a única atuação satisfatória ocorre com a relação apropriada com o companheiro. Se o ator se faz compreender claramente como ser humano por seu companheiro de cena, o público o entenderá, a atuação se fará verdadeira".
Uma observação interessante de uma das alunas- atrizes foi em relação a decorar ou não o texto. Diz ela:" "Penso que é necessário ter intimidade com o texto para o rádio, mas quando está decorado não é bom. O momento certo para a gravação final é um pouco antes de isto acontecer".

Na situação radiofônica não decorar o texto pode ser uma forma de não deixá-lo mecânico. Ao mesmo tempo, ele funciona como um roteiro para a gravação ou transmissão ao vivo. É como se manter os olhos no papel tivesse o efeito de concentrar a atenção no falar e no ouvir, tirar do olhar a necessidade premente que tem o ator no teatro. O texto é, então, um roteiro a guiar a atuação.

Fizemos ainda uma gravação em que fomos parando e refazendo falas e intenções. Minha direção também se fez voz ao microfone, gravando. Aqui fizemos isto com os fones. Foi uma experiência interessante, pois foi como se colocássemos nossa conversa noutro patamar, como se criássemos uma peça dentro da peça.

Para a gravação da versão final deste exercício havia conseguido um espaço numa rádio. Não tínhamos muito tempo de estúdio e não haveria muitos recursos para uma montagem como imaginávamos. Assim, simplifiquei os efeitos e fiquei com as músicas. O trabalho correu bem, até porque decidimos encontrar-nos antes e ensaiar em nossa sala de trabalho, o que se mostrou bastante eficaz. As atrizes chegaram para a gravação, aquecidas e disponíveis.

A audição da peça mostra um jogo muito interessante das falas que enfatizam o absurdo daquilo que estão dizendo. A variação do tempo das pausas, o ritmo, ora acelerado ora ralentado, evidenciam o trabalho com os fones. $\mathrm{O}$ jogo com as peças de reposição, produtos da fábrica, trazem a estranheza e o humor desejado. A evolução da relação das duas mulheres vai se desnudando no decorrer da peça de uma forma muito sonora.

7 Notas retiradas dos diários de trabalho das alunas-atrizes durante fase da pesquisa $O$ trabalho do ator voltado para um veículo radiofônico. 
Microfone, espaço, fones de ouvido, gravações, planos, tempo, duração, ritmo, performance. Dizer e ouvir, dizer para alguém, dizer com alguém. Contracenação é também um repertório de escuta. Brecht (1978, p.123) refere-se ao trabalho conjunto de atores, seja em formação ou na vida profissional, que remete à idéia de contracenar como escuta do outro:

\begin{abstract}
A aprendizagem de cada ator deve-se processar em conjunto com a dos outros atores, e, da mesma forma, a estruturação de cada personagem tem de ser conjugada com a das restantes. É que a unidade social mínima não é o homem, e sim dois homens. Também na vida real nos formamos uns aos outros.
\end{abstract}

Contracenar mostrou-se uma ação de escuta sensível com todos os sentidos. E mais uma vez nos fez transportar esta ideia para o teatro. Mostrando que a fala mecânica implica em escuta inerte e numa cena morta. No rádio a fala sem vida, sem organicidade faz sucumbir a atmosfera.

O uso dos fones de ouvido passou a ser um auxiliar potente na contracenação. Ele dá o retorno imediato ao ator do seu dizer e potencializa o diálogo com o companheiro de cena. Os atores atuam com todo o foco na escuta de si e do outro. É perceber na prática a vivência de ser um e outro ao mesmo tempo, ator e ouvinte, podendo assim tomar as rédeas de sua atuação no instante mesmo da sua realização.

Temos um repertório de escuta que nos faz criar sons e vozes e ambientes ao mesmo tempo que nos faz reconhecer espaços e timbres. É desse repertório que nasce a composição vocal do ator e é o que sustenta a imaginação do ouvinte.

\section{Referências bibliográficas}

BALSEBRE, Armand. El lenguaje radiofonico. Madrid: Cátedra, 1994.

BRECHT, Bertolt. Estudos sobre Teatro. Rio de Janeiro: Nova Fronteira, 1978.
CHEKHOV, Michael. Método de actuación de Stanislavski. In: COLE, Toby (org.) Actuación. México: Editorial Diana, 1983. (1947).

FORTUNA, Marlene. A performance da oralidade teatral. São Paulo: Annablume, 2000.

KLIPPERT, Werner. Elementos da linguagem radiofônica. In: SPERBER, George Bernard. Introdução a Peça Radiofônica. São Paulo: Editora Pedagógica e Universitária, 1980.

ORLANDI, Eni Pucinelli. As formas do silêncio. No movimento dos sentidos. Campinas: Editora da Unicamp, 2002.

PEIXOTO, Fernando. Descobrindo o que já estava descoberto. In: SPERBER, George Bernard. Introdução à Peça Radiofônica. São Paulo: Editora Pedagógica e Universitária, 1980.

SHAFFER, R. Murray. O ouvido pensante. São Paulo: UNESP, 1991. 